\title{
XXXIV. Note on a very convenient method of accurately focussing and adjusting the image of a laboratory light source upon the slit of a spectrograph
}

\section{G.A. Hemsalech}

To cite this article: G.A. Hemsalech (1920) XXXIV. Note on a very convenient method of accurately focussing and adjusting the image of a laboratory light source upon the slit of a spectrograph , Philosophical Magazine Series 6, 40:237, 316-317, DOI: 10.1080/14786440908636128

To link to this article: http://dx.doi.org/10.1080/14786440908636128

\section{Published online: 08 Apr 2009.}

Submit your article to this journal ए

Џll Article views: 2

Q View related articles ¿

4 Citing articles: 1 View citing articles ๘ 
XXXIV. Note on a very Convenient Method of Accurately. Focussing and Adjusting the Image of a Laboratory Light Source upon the Slit of a Spectrograph. By G. A. HeMSALECH *

$\mathrm{T}$ is often necessary in exact spectroscopic investigations to project by means of a lens a sharply defined image of the source of light upon the collimator slit, for the purpose of differentiating between the radiations emitted by various regions in the source. In this way Sir Norman Lockyer, to whom this most important method of spectroscopic observation is due, discovered the so-called long and short lines in the arc and spark. In order to make the requisite adjustinents it generally suffices, especially in the case of such bright sources as the are or spark, to observe the image on the slit and to move either the source or the lens until the image appears quite sharp. But in the case of a feeble source of light, such as an uncoloured flame, or a source which is limited in duration as, for example, a small high temperature plate resistance furnace, the usual method of adjusting the image on the slit becomes difficult and even impracticable. Having become confronted with this inconvenience in the course of iny experiments with plate furnaces, I was led to try several alternative methods, and finally adopted one which not only entirely solved the difficulty for the furnace, but was also found to be equally well applicable to the flame, arc, or spark. This method is merely the converse of the old one, and consists in focussing the slit upon. the source of light. It is really so simple that I bave no doubt of it having already been used by others, but since I have not seen a record of it in any work on spectroscopy, and also in view of its unquestionable usefulness, I venture to give a short account of it for the benefit of those spectroscopists who may not yet be acquainted with it.

Let us suppose that the projection objective $O$ has been centred with respect to the axis of the collimator by means of some suitable method, as, for example, the one I have given in my thesis $\dagger$, and that the slit $S$ is at one of the foci of $O$. If a spark passing between the electrodes $\mathrm{E}$ and $\mathrm{E}^{\prime}$ be placed at the conjugate focus of $O$ its image will coincide with $S$. But conversely also an image of the slit $S$ is formed at $\mathrm{T}$ coincident with the spark-gap. It is this image $\mathrm{I}$ which is observed and made to coincide with the tips of the electrodes $\mathrm{E}$ and $\mathrm{E}^{\prime}$. In practice the procedure adopted is as

* Communicated by the Author.

$\dagger$ IIemsalech, Thèses de Doctorat, Paris, 1001, p. 33. 
follows : the slit $S$ is illuminated by means of an ordinary incandescent lamp placed within 1 or 2 yards from the former. Its image $\mathrm{T}$ is then directly viewed by the unaided eye, or if greater accuracy be desired, by means of the small

Fig. 1.

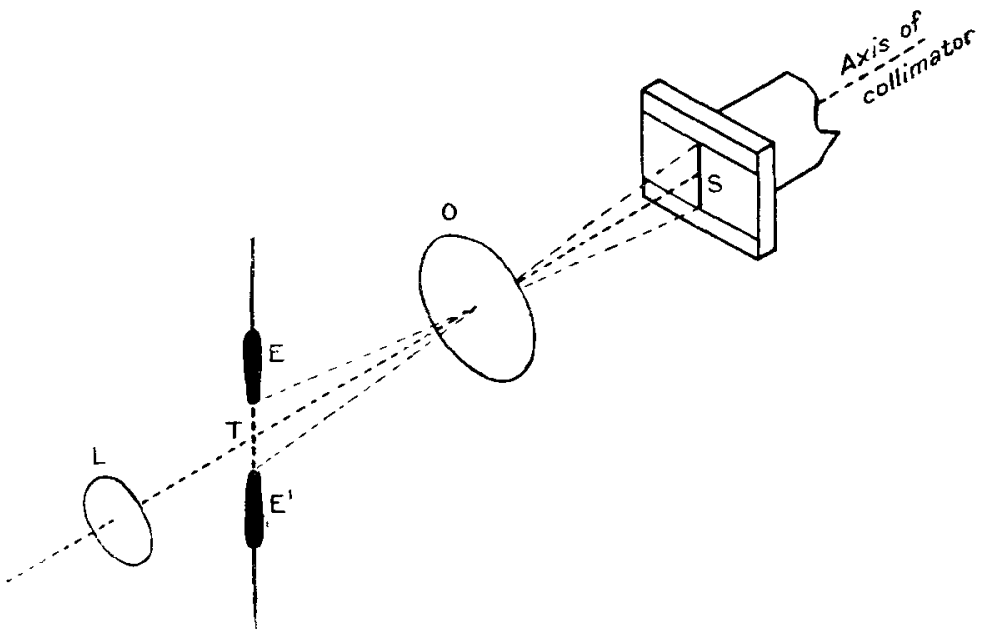

Illustrating method of focussing image of Light Source on slit of Spectrograph.

magnifying lens $L$. The electrodes $E$ and $E^{\prime}$ are then moved into position and adjusted until the slit image and spark-gap are seen to coincide. Any region of the sparkgap can in this way be brought into coincidence with any part of the slit image without much trouble. Accuracy of focus is tested by displacing the eye sideways, and the least deviation from coincidence will immediately reveal itself by a parallax effect between the slit image and the tips of the electrodes. If the source be a flame the orifice of the burner may be brought into coincidence with the slit image, or, if the region to be examined be too far above the burner a piece of wire held in that region will serve the purpose.

Evidently the same method applies when it is desired to adjust the position of the objective $O$. In this case the spark-gap between $E$ and $E^{\prime}$ is placed in line with the optic axis of the collimator at a distance from the slit which corresponds to the focal length of $O$ and the size of image required. The slit image $\mathrm{T}$ is then made to coincide with the spark-gap by adjusting the position of the objective $O$.

Manchester, May 1920. 